\title{
A ASSISTÊNCIA DE ENFERMAGEM NO SERVIÇO DE EMERGÉNCIA PEDIÁTRICA
}

Condorimay YRT, Vendruscolo DMS. A assistência de enfermagem no serviço de emergência pediátrica. Rev Latino-am Enfermagem 2004 maio-junho; 12(3):477-84.

Este artigo de abordagem qualitativa tem como objetivo caracterizar a atuação da enfermeira na assistência à criança em situação de emergência, numa unidade de atendimento pediátrico de um hospital no interior de São Paulo, através de entrevista semi-estruturada, com oito enfermeiras. A entrevista compreendeu questões sobre o perfil profissional e, a seguir, a questão norteadora. A técnica de análise de conteúdo proposta por Bardin (1997) orientou a análise, sendo identificado o tema: a enfermeira como mediadora do atendimento à criança na sala de emergência, a partir de quatro subtemas: o planejamento da assistência à criança, admitindo e avaliando-a, atuando na assistência a ela e a sua família e capacitação para o atendimento. A atuação da enfermeira exige conhecimento, capacitação técnica e tecnológica, habilidade e agilidade, tomada de decisões, trabalho de equipe, manifestando segurança, calma, empatia e racionalidade, para atender à criança e a sua família numa situação de emergência.

DESCRITORES: enfermagem pediátrica; serviços médicos de emergência; família

\section{NURSING ASSISTANCE IN PEDIATRIC EMERGENCY SERVICES}

This qualitative study aims to characterize nurses' actions in care for children during emergency situations, at a pediatric unit from a hospital in the interior of São Paulo State, Brazil, by means of semi structured interviews with eight nurses. The interview included questions about professional profile and, next, the research question. The analysis was guided by Bardin's content analysis (1997), which resulted in the theme: the nurses as a mediator in child care in the emergency room, based on four subthemes: child care planning, child's admission and evaluation, acting in child and family care and care training. Nursing actions in emergency situations with children and their families demand knowledge, technical and technological training, ability and agility, decision-making and teamwork, transmitting security, tranquility, empathy and rationality.

DESCRIPTORS: pediatric nursing; emergency medical services; family

\section{ASISTENCIA DE ENFERMERÍA EN EL SERVICIO DE EMERGENCIA PEDIÁTRICA}

Este articulo de abordaje cualitativo tiene como objetivo caracterizar la actuación de los enfermeros en la asistencia al niño en situación de emergencia, en una unidad de atención pediátrica de un hospital en el interior de São Paulo, Brasil, mediante entrevistas semi-estructuradas con ocho enfermeras. La entrevista comprendió preguntas sobre el perfil profesional y luego una pregunta norteadora. La técnica de análisis de contenido propuesta por Bardin (1997) orientó el análisis, siendo identificado el tema: la enfermera como mediadora en la atención al niño en la sala de emergencia, a partir de cuatro subtemas: La planificación de la asistencia al niño, admisión y evaluación del niño, actuación en la asistencia al niño y su familia y capacitación para la atención en la sala de emergencia. La actuación de los enfermeros exige conocimiento, capacitación técnica y tecnológica, habilidad e agilidad, toma de decisiones, trabajo de equipo, manifestando seguridad, calma, empatía y racionalidad, para atender al niño y su familia en situación de emergencia.

DESCRIPTORES: enfermería pediátrica; servicios médicos de urgencia; familia

\footnotetext{
${ }^{1}$ Professora de la Universidad Nacional Mayor de San Marcos - Escuela de Enfermería (Lima-Peru), Aluna de Mestrado do Programa Enfermagem em Saúde Pública, e-mail:yopitact@yahoo.com.br; ${ }^{2}$ Orientador, Professor Doutor. Escola de Enfermagem de Ribeirão Preto, da Universidade de São Paulo, Centro Colaborador da OMS para o desenvolvimento da pesquisa em enfermagem
} 


\section{INTRODUCÃO}

A cada ano morrem cerca de 12 milhões de crianças, antes de chegar aos cinco anos de idade, muitas delas, durante o primeiro ano de vida, sobretudo nos países em desenvolvimento. Sete, de cada dez, dessas mortes devem-se a infecções respiratórias agudas (principalmente pneumonia), à diarréia, ao sarampo, à malária ou desnutrição, e, freqüentemente, a uma combinação dessas afecções ${ }^{(1)}$.

Quando está na fase aguda da doença ou de acidentes, a criança chega aos serviços emergenciais com alto risco para a morte, exigindo da equipe de assistência o desenvolvimento de suas potencialidades para prover o atendimento emergencial. Cabe à equipe de enfermagem a responsabilidade pelos cuidados intensivos ao paciente crítico, por meio da avaliação permanente, da vigilância, $\mathrm{e}$ da realização de procedimentos e técnicas que complementam a terapêutica médica. Deve dispor igualmente de protocolos para a assistência de enfermagem, garantindo a continuidade de um trabalho integrado com a equipe médica, atuando na orientação $e$ no acolhimento dos familiares.

Nas situações emergenciais, a criança é quase sempre a principal vítima, necessitando de uma atenção especial, dadas as peculiaridades biológicas e psicológicas e as características próprias desse grupo populacional no país, sujeito aos agravos decorrentes das doenças prevalentes na infância, necessitando de recursos materiais e humanos especializados para $\mathrm{o}$ atendimento emergencial.

Diversos fatores colocam a criança em situação de risco. Entre as causas que demandam assistência nas unidades de atendimento pediátrico estão as doenças respiratórias, os estados convulsivos, as intoxicações, os acidentes e traumas, provocando, muitas vezes, a parada cardiorrespiratória, que constitui a emergência médica de maior importância na área pediátrica. Os processos infecciosos, parasitários e traumáticos, na maioria das vezes, constituem as principais causas de ingresso a essas unidades.

Os profissionais que atuam na unidade de emergência devem receber treinamento específico, tanto técnico e científico, quanto uma educação continuada voltada para o autoconhecimento, o que exige deles domínio de suas próprias emoções e conhecimento de seus limites e de suas possibilidades ${ }^{(2)}$. Por outro lado, a angústia e a ausência de informações aos familiares são também fontes de tensão nesse ambiente.

$O$ atendimento em emergência cardiorrespiratória e em ressuscitação cardiopulmonar desenvolve-se, a partir da década de 60 do século passado, por meio de programas e procedimentos estandarizados, decorrentes de propostas de organizações internacionais para 0 treinamento em urgências e em medidas de técnicas básicas e avançadas. Na década de 80, foi padronizado 0 atendimento pediátrico e neonatal para ressuscitação cardiopulmonar (RCP) denominado Suporte Básico de Vida e Suporte Avançado de Vida Pediátrico. Esses cursos de treinamento em RCP pediátrica foram introduzidos no Brasil, a partir de 1998, pela Sociedade Brasileira de Cardiologia, em convênio com a Sociedade Brasileira de Pediatria, priorizando a capacitação do profissional médico e, posteriormente, dos profissionais de enfermagem.

Os serviços de pronto atendimento, sobretudo nos grandes centros urbanos, recebem alta demanda de pacientes, e a tendência da equipe é trabalhar com rapidez e eficácia para minimizar as situações de risco de vida. Diante de uma criança em situação de risco iminente, ocorre, nesses profissionais e, sobretudo, na equipe de enfermagem, uma diversidade de respostas subjetivas, produto de uma reação intensa a essas experiências e das relações que se estabelecem com a criança e sua família, como conseqüência da sensibilidade característica dos seres humanos e, em especial, dos profissionais que atuam no serviço pediátrico.

A decisão de tomar como objeto de estudo a atuação da enfermeira na assistência à criança, diante de uma situação de emergência, deve-se à verificação de que, no âmbito da enfermagem, poucos estudos têm privilegiado o referido tema e, nesse sentido, este trabalho configurase como um espaço pouco explorado.

Assim, este estudo teve como objetivo caracterizar a atuação da enfermeira na assistência à criança, em situação de emergência.

\section{METODOLOGIA}

Para responder ao objetivo proposto nesta pesquisa de caráter descritivo e exploratório, utilizamos a abordagem qualitativa $^{(3)}$, que trabalha com o universo de significados, motivos, aspirações, crenças, valores e atitudes, o que corresponde a um espaço mais profundo 
das relações, dos processos e dos fenômenos que não podem ser reduzidos à operacionalização de variáveis. Como instrumento de coleta de dados, optamos por utilizar a técnica da entrevista semi-estruturada, com auxílio de um gravador. A questão norteadora que orientou 0 desenvolvimento deste estudo foi assim definida:

- Como é o atendimento da criança numa situação de emergência? Fale um pouco sobre isso.

O projeto de pesquisa foi encaminhado ao Comitê de Ética em Pesquisa para a revisão dos aspectos éticos da pesquisa e conseqüente autorização para a realização deste estudo, segundo a regulamentação de pesquisas em seres humanos ${ }^{(4)}$.

O desenvolvimento deste estudo teve como cenário a Unidade de Atendimento Pediátrico da Unidade de Emergência de um hospital de ensino público, que é centro de referência para esse atendimento, num município do interior do estado de São Paulo, e que atende a crianças em situação de risco iminente. O fluxograma de atendimento à clientela pediátrica é realizado pela Central Única de Regulação Médica, por meio da Ficha de Referência preenchida pelo serviço de saúde de origem, sejam as Unidades Básicas de Saúde (UBS), outros hospitais ou serviços de outras regiões. A unidade possui 14 leitos, dos quais 13 são para o atendimento clínico e um para estabilização clínica. Conta com atuação de 10 enfermeiras, as quais assumem também o Serviço de Enfermaria Pediátrica, 11 auxiliares e um técnico de enfermagem, esses últimos só no Atendimento Pediátrico, todos cumprindo jornada de 30 horas, e com uma equipe médica especializada e permanente. Quanto à estrutura física, a unidade possui ambiente destinado à atenção direta dos pacientes que estão em observação, salas de avaliação médica, sala de isolamento e a sala de emergência para atenção ao paciente grave ou em parada cardiorrespiratória (PCR).

A população estudada foi constituída pela totalidade das enfermeiras que trabalham na Unidade de Atendimento Pediátrico, tendo como critério para inclusão na pesquisa as enfermeiras que atuavam na unidade por um período maior de um ano. A utilização desse critério de inclusão busca atender às especificidades da pesquisa qualitativa ${ }^{(5)}$, ao se definir a população a ser estudada, pois a preocupação não é com generalizações, mas, sim, com o aprofundamento e a abrangência da compreensão da realidade vivenciada pelos sujeitos. Participaram como sujeitos da pesquisa oito enfermeiras. A entrevista foi agendada previamente, durante o expediente de trabalho, utilizando um local reservado que garantisse a privacidade.

A análise, por sua própria natureza e subjetividade, foi fundamentada na abordagem qualitativa, sendo sistematizada conforme a técnica de análise de conteúdo, mais especificamente a análise temática, proposta por $\operatorname{Bardin}^{(6)}$. Essa técnica consiste em descobrir os núcleos de sentido que compõem a comunicação, cuja presença e freqüência podem ter significados para o objetivo escolhido. Essa autora assinala que a unidade de significado pode ser recortada em idéias constituintes, em enunciados ou em proposições portadoras de significados isolados. Para efeito deste trabalho, as unidades de significado constituíram-se em categorias de análise decorrentes da vivência dos enfermeiros no atendimento à criança, numa situação de emergência. $\mathrm{Na}$ operacionalização ou tratamento dos dados desta proposta, seguimos os seguintes passos: ordenação dos dados (com a transcrição das gravações, releitura do material e organização dos relatos); classificação dos dados (elaboração dos núcleos de sentido) e análise final (quando são estabelecidas as articulações entre os dados e a teoria) ${ }^{(7)}$.

Passaremos, a seguir, a apresentar os resultados e a discussão.

\section{RESULTADOS E DISCUSSÃO}

Conforme planejado neste estudo, descreveremos, inicialmente, o perfil profissional das enfermeiras que participaram desta pesquisa, a seguir, a análise temática com o tema: a enfermeira como mediadora do atendimento à criança em situação de emergência.

Caracterização dos sujeitos

As características sociodemográficas e profissionais das enfermeiras estudadas revelam que, nesse grupo, predomina a faixa etária de 30-35 anos, o estado civil solteira, a religião católica, sendo que a maioria não tem filhos. Quanto à formação profissional, duas dessas enfermeiras possuem apenas o curso de graduação; outras duas, a Habilitação em Enfermagem Médico-Cirúrgica, e quatro delas, Licenciatura em Enfermagem. Quanto à formação em cursos de pósgraduação, apenas uma concluiu o curso de 
Especialização, lato sensu, em Enfermagem Pediátrica e Neonatologia, e nenhuma tem pós-graduação stricto sensu. O tempo de serviço dessas profissionais na instituição é variável, sendo que quatro possuem mais de nove anos de trabalho, três delas, quatro anos, e apenas uma, com um ano e seis meses na Unidade de Emergência.

Como política de capacitação profissional, a Unidade de Emergência, desde o ano 2000, vem oferecendo cursos de treinamento na área de emergência pediátrica como o Suporte de Vida Avançado em Pediatria (SAVP) ou de Pediatrics Advance Life Support (PALS). Até o momento, seis dessas enfermeiras realizaram essa capacitação.

\section{Análise temática}

O material apresentado a seguir é constituído da síntese extraída dos conteúdos das falas dos discursos das oito enfermeiras participantes da pesquisa a qual revelou o tema central, identificando a atuação da enfermeira, a partir de seu papel mediador na assistência à criança, na sala de Emergência.

A enfermeira como mediadora do atendimento à criança em situação de emergência

Esse tema constitui-se a partir dos subtemas: o planejamento da assistência à criança na sala de emergência, a admissão e avaliação da criança na sala de emergência, atuação da enfermagem na assistência à criança e sua família e a capacitação para o atendimento na sala de emergência, os quais passamos a descrever: - O planejamento da assistência à criança na sala de emergência

A Unidade de Atendimento Pediátrico é a porta de entrada para receber crianças em risco de perder a vida, sendo referência no município, para o atendimento de emergência, e, dessa forma, a assistência à criança deve ser prevista e planejada, para qualquer atendimento emergencial, como mencionado pelas entrevistadas:

- aqui já há uma organização e planejamento, no fluxo dessa criança, dentro da unidade, (...) (E6).

- a sala é preparada para trabalhar com paciente agudo que tem toda a chance de fazer uma PCR (E4).

- na passagem de plantão, a primeira coisa que a gente faz é verificar se o ambulatório está em ordem, o equipamento, se está tudo pronto, pode ser que falte alguma coisa de outro plantão, a primeira rotina nossa é isso (E1).

No atendimento numa situação de emergência, a enfermeira desenvolve diferentes ações, dentre elas a de administrar os recursos humanos, técnicos e auxiliares de enfermagem, como também garantir a disponibilidade e a qualidade de recursos materiais e de infra-estrutura que permitam à equipe atuar no atendimento emergencial, sendo esses aspectos identificados nas falas que seguem: - a gente deixa tudo organizado, a sala montada, a medicação de urgência preparada, o respirador, o material de entubação, (...) (E7). - se você tem um conhecimento sobre o que é a parada e como você vai atender essa parada, você tem que ter material, (...) (E8).

- graças a Deus, hoje temos materiais, senão fica difícil, porque você fica com aquela ansiedade, aquele estresse (E5).

Como parte da organização desse ambiente, a monitorização da criança e a sua avaliação durante a Parada Cardiorrespiratória são vitais no atendimento emergencial, possibilitando informações para prosseguir com medidas avançadas de Reanimação Cardiopulmonar. Observa-se, nas falas das enfermeiras entrevistadas, a preocupação pela organização do serviço:

- a gente tem aparelho, como identificar rapidamente o que vai, o que está acontecendo, (...) (E6).

- ao reverter uma parada, tantas coisas acontecem que nada pode atrapalhar, e realmente nenhuma coisa pode atrapalhar, pois é a vida que está em nossas mãos, o êxito está no tempo de execução, (...) (E8).

Além da manutenção da sala de emergência em condições para pronto uso, a maior parte das atividades executadas é de competência do enfermeiro e, mesmo aquelas ações privativas do médico, requerem a colaboração desses profissionais, para as quais têm que estar preparados ${ }^{(8)}$.

- você pensa em tudo para salvar essa criança, você corre, punciona uma veia rápido, se ela não tiver nenhum acesso, procura o material de que precisa, a cânula que vai ser usada, (...) (E2).

- já tem uma organização, fez a medicação, os aparelhos já estão todos ao redor da maca, os profissionais já estão esperando, já sabem como agir, (...) (E6).

A enfermeira torna-se um elemento importante dentro da equipe, na atenção à criança, tendo um papel decisivo junto ao médico, conforme as falas das enfermeiras:

- a gente já sabe o que o médico vai precisar, nessa sala já tem tudo o que vai precisar, por isso é que o enfermeiro é importante, (...) (E4). 
- o enfermeiro prepara toda a sala, (...) prepara material para a emergência, deixa tudo pronto, (...) (E1).

- a gente vai organizando tudo, (...) o médico toma a frente, já vai pedindo, (...) (E3).

Para as enfermeiras entrevistadas, as condições de trabalho devem garantir os equipamentos e materiais necessários para o atendimento emergencial em pediatria, e a falta deles limita a assistência à criança, como mencionado pelo grupo:

- eu trabalho no pronto-socorro para criança grave, e, de repente, não tenho um monitor cardíaco, não adianta ter gente habilitada e não ter um monitor para poder colocar o paciente, (...) o paciente não tem veia, não adianta saber fazer intra-óssea e não ter agulha especial, então tem que ter o material (E4).

- agora, depois do PALS, a gente está conseguindo ter o material com mais facilidade, (...) (E6).

A atuação mediadora do enfermeiro na Unidade de Atendimento Pediátrico contribui para manter a organização e o funcionamento da sala de emergência, por meio do controle de materiais e aparelhos, da realização de protocolos de atendimento e capacitação da equipe de enfermagem, com a finalidade de garantir uma assistência ótima, rápida e eficaz para diminuir o risco de seqüelas e incapacidades da criança em situação de emergência.

- A admissão e avaliação da criança na sala de emergência

A admissão da criança na Unidade de Atendimento Pediatrico faz-se por meio da Central Única de Regulação Médica (CURM), que tem como função controlar a demanda pelos leitos hospitalares, por meio da racionalização e utilização dos recursos, preservando o atendimento imediato às situações que colocam a vida da criança em perigo iminente. A equipe técnica da Unidade de Emergência passou a racionalizar a utilização dos recursos hospitalares, preservando espaços aptos a atender procedimentos de alta complexidade e garantindo 0 atendimento imediato às situações de perigo iminente de vida ${ }^{(9)}$. Nesse sentido, a CURM tem sido um importante meio de informação para a equipe de atendimento pediátrico, sobre o perfil da criança que vai dar entrada no serviço. Assim as enfermeiras relatam:

- agora, com o regulador entre os hospitais do SUS, os pacientes estão sendo distribuídos melhor, antigamente você punha o paciente no chão, hoje, essa realidade da UE não existe mais, (...), agora facilitou porque a gente não tem esse excesso de paciente mais, (...) (E4).

- da regulação, o médico liga e fala que a criança vai chegar assim, assim, assim (E5).
- com a regulação, isso mudou. Antigamente as crianças chegavam de qualquer jeito, agora não, elas vêm com uma referência, porque já tem uma estrutura lá fora, o SAMU, que dá o pré-atendimento hospitalar, (...) (E6).

A avaliação na sala de emergência é a etapa inicial e fundamental no atendimento aos pacientes, pois visa a detectar os distúrbios que ameaçam a vida, no sentido de estabelecer as prioridades para nortear $\mathrm{o}$ atendimento $\mathrm{e}$ corrigir os distúrbios respiratórios e metabólicos em tempo hábil, garantindo a manutenção das funções vitais para salvaguardar a vida, levando em consideração os aspectos anatômicos e psicológicos da criança ${ }^{(10)}$. O enfermeiro deve estar capacitado para o atendimento à criança nessa fase inicial.

A vivência das enfermeiras, na sala de emergência, evidencia a realização da avaliação primária, que resulta na garantia de uma ventilação adequada da criança. Elas relatam que:

- a gente já olha e já percebe que não está bem, então já deixamos tudo preparado, (...) (E3).

- a primeira coisa que eu bato o olho é se a paciente precisa de oxigênio e tem uma veia pega, (...) (E4).

A atuação do enfermeiro implica organização, seqüência lógica das ações emergenciais e delegação de funções para que cada membro da equipe atue de forma sincrônica, especialmente naqueles procedimentos que são concomitantes para manter uma ventilação adequada. Assim, elas se preparam para dar atenção, conforme as falas:

- é tudo uma seqüência, é uma coisa planejada, organizada, e todo mundo está sabendo o que está fazendo, (...) (E6).

- a gente começa a distribuir as tarefas (...) (E1).

- enquanto o médico não chega, a gente vai fazendo nossa parte, oxigenando, (...) (E8).

- geralmente a gente já sabe a idade da criança, deixamos as cânulas separadas, o soro pendurado, o abocat separado (...) então eu vejo minha responsabilidade (E7).

Para as enfermeiras, o atendimento em emergência pediátrica exige experiência e capacitação, iniciando-se com a avaliação da criança, desobstrução de vias aéreas, ventilação, punção de veia periférica e a ajuda na compressão torácica externa, uma vez que a Ressuscitação Cardiopulmonar independe de um diagnóstico etiológico, e o fator tempo prima para salvar a vida da criança.

- Atuação da enfermagem na assistência à criança e a sua família na sala de emergência 
Na sala de emergência, exige-se do enfermeiro conhecimento, capacitação e rapidez para a tomada de decisões pertinentes ao diagnóstico, para com um único paciente, ou com um grande número de vítimas, desempenhando o papel de mediador da assistência na sala de emergência e permitindo diminuir o risco de morte na criança ${ }^{(11)}$. Nesse sentido, o grupo de enfermeiras relata:

- a gente sabe que vai chegar uma criança e que precisamos tomar frente e organizar; às vezes, pedimos para algum funcionário ficar na sala de emergência, deixamos um outro funcionário fora, vendo as outras crianças, porque não podemos esquecer que temos outras crianças, na sala de hidratação ou no isolamento, e, às vezes, pode ser que a criança não esteja bem, (...) (E3).

- todos os profissionais se dirigem para essa sala, o necessário seria o médico contratado, um R2, um R1, o enfermeiro e um auxiliar de enfermagem, o necessário para a gente atender, o ideal são essas cinco pessoas (E4).

No setor de emergências, os enfermeiros devem adotar estilos de liderança participativa, compartilhar e ou delegar funções, sendo as principais habilidades, para o gerenciamento da assistência de enfermagem, a comunicação, o relacionamento interpessoal, a liderança, a tomada de decisão e a competência técnica ${ }^{(12)}$. Essas capacidades e competências são reveladas pelas enfermeiras:

- os médicos, quando tem uma parada, querem o enfermeiro de lado, já é padronizado, tem uma parada, o enfermeiro está aí do lado (E1).

- você pega um pessoal que já está habilitado, que já trabalha, já tem treinamento certinho, a parada é uma coisa programada, a diferença é que ela é mais rápida, (...) primeiro faz isso, isso, isso, a parada tem que seguir um protocolo, a diferença é que você faz de uma forma mais rápida (E4).

O grupo estudado mostrou haver coesão no atendimento de enfermagem:

- no ambulatório, tem pouco funcionário, são funcionários bons que trabalham, são funcionários que você não tem problema, eles trabalham mesmo, eles cooperam (E2).

- se você tem uma equipe coesa, está certo, (...) (E3).

- pessoas que já estão acostumadas com esse tipo de atendimento, já são pessoas preparadas, treinadas (E1).

A equipe também tem que estar preparada para tomada de decisões independentes e complementares, sob o comando único de um líder, que transmita segurança e confiança. O grupo de enfermeiras entrevistadas assim se manifesta sobre esse aspecto:
- nós, da equipe de enfermagem, somos fixos, nós não trocamos, a equipe médica troca, de dois em dois meses, (...) (E2).

- por insegurança, são muito desorganizados, a liderança nunca fica com o residente, a liderança sempre fica com o médico contratado ou com a enfermeira, (...) você tem que ter como liderança, a pessoa mais calma, (...) tem médico que consegue estressar todo mundo, então o atendimento é ruim (E4).

Além do comprometimento físico e vital que acomete a criança numa emergência, não devemos esquecer a carga emocional, o sofrimento e a dor dos pais, fatos que geram tensão e angústia no ambiente de atendimento. As famílias necessitam de comunicação e informações para aliviar suas emoções, e a enfermeira deve possuir sensibilidade especial para lidar com os familiares, demonstrando capacidade comunicativa adequada a cada situação e favorecendo formas de conforto físico e espiritual, como acompanhamento, área reservada à família, ou disposição do telefone ${ }^{(13)}$. Quando a criança foi estabilizada ou foi a óbito, as enfermeiras procuram os pais:

- quando a criança está bem, está viva, eu falo: a criança está estável, está bem, ela vai melhorar, está entubada, (...), você explica, até que o médico chegue junto à família (E5).

- não consigo passar pelo pai ou a mãe sem dar uma satisfação, sem dar uma palavra de apoio, ou simplesmente colocar a mão na mãe e falar mãe, reza, ora, pede para Deus, pede a ele para confortar seu coração, porque estamos fazendo o impossível, (...) (E7).

As reações familiares dependem de múltiplos e complexos fatores, sendo que o impacto emocional de uma doença aguda, acidente ou do falecimento de um familiar de forma intempestiva provoca uma série de conflitos emocionais que afetam a unidade familiar. Nesse momento, os integrantes da equipe passam a compartilhar as manifestações psicossociais da família, podendo tornarse elementos de transmissão de calma e tranqüilidade. Diferentes situações manifestadas por sentimentos de estresse e de dor fazem com que a enfermeira se sinta limitada na atenção à família. Ela pode desenvolver uma série de mecanismos e estratégias para atuar com os familiares, entretanto, superar essas situações é difícil para qualquer membro da equipe ${ }^{(14-15)}$.

- Capacitação para o atendimento na sala de emergência

Nos serviços de pronto atendimento, é recomendada a capacitação dos profissionais por meio de cursos especializados e treinamento em serviço, e o aprimoramento profissional da equipe faz parte desse processo de capacitação. O grupo de enfermeiras reconhece a necessidade da capacitação para prestar 
assistência a crianças em situações emergenciais, destacando fatores importantes como a habilidade e o tempo. Nesse sentido, elas relatam que:

- precisam de habilidade em técnicas de enfermagem, habilidade para punção, para manuseio de materiais, para assistir uma parada cardíaca; você está junto com o médico, tem que passar o material que está pedindo, preparar a medicação, tem que ser hábil nessa hora, se demorar e não ter habilidade, conta tempo, e o tempo é importante nessa hora (E8).

- porque o tempo corre e podemos conseguir reverter o quadro. Se demorar muito, vai ser pior para a criança, (...) (E3).

Para a competência e as habilidades esperadas, é fundamental um treinamento específico de todos os membros da equipe, além de uma definição clara das funções, sempre sob a liderança do enfermeiro ${ }^{(16)}$. A equipe de enfermagem tem que ter um líder para trabalhar sincronicamente com a equipe médica e, nesse aspecto, é relatado:

- é fundamental que tenha um treinamento específico. Eu sinto que não sei tudo, apesar dos cursos que eu fiz; eu gostaria que uma pessoa que soubesse muito mais viesse compartilhar as experiências conosco; acho que é muito importante, por isso nunca se pode deixar de estudar, sempre tem que procurar melhorar cada vez mais; esse papel da enfermeira é fundamental (E3).

- a gente tem trabalhado com o mecanismo do PALS, o ABCDE, a gente tenta trabalhar em conjunto; os médicos residentes são obrigados a seguir o PALS, (...) por exemplo, se tem um enfermeiro que está ajudando na fase $A$ e $B$ junto com o médico, então eu entro para ajudar e vou para avaliar o $C$, (...) (E4).

Atualmente, é consenso internacional trabalhar em emergências pediátricas com o protocolo do PALS, ficando sob a responsabilidade da instituição facilitar a acessibilidade dos membros da equipe a esses cursos periodicamente. Essa atualização é recomendada a cada dois anos, pois a eficácia de uma habilidade motora para a reanimação cardiopulmonar depende da freqüência de sua realização, sendo difícil manter a destreza necessária para esse tipo de assistência. As enfermeiras do Atendimento Pediátrico estão sendo capacitadas pelo protocolo do PALS, e esse treinamento provê os conhecimentos e habilidades para que a equipe atue organizadamente ${ }^{(17-18)}$. As enfermeiras descrevem:

- a capacitação e a qualificação por meio do suporte básico de vida em pediatria facilita atender à criança em PCR (E6).

- seria importante a formação do enfermeiro através do PALS (...) para nós, o PALS é muito puxado, porque é voltado para o médico, você tem a teoria e depois tem a prática montada em estações,(...) é cansativo, mas você tem outra visão do paciente (E4).

$\mathrm{Na}$ análise que efetuamos até então, é importante ressaltar que a atuação da enfermeira como elemento de integração na organização da assistência à criança na sala de emergência da Unidade de Atendimento Pediátrico é resultado da experiência profissional com a criança hospitalizada e sua família, do planejamento da unidade com relação aos recursos humanos e materiais, do relacionamento interpessoal da equipe, a criança e sua família, do conhecimento e habilidade decorrentes da capacitação em emergência pediátrica com a educação continuada da equipe de enfermagem para que se possa garantir o cuidado emergencial.

\section{CONSIDERAÇÕES FINAIS}

A realização deste trabalho permite considerar que a assistência à criança em situação de emergência, em decorrência de sua complexidade e do recorte deste estudo, não se esgota nesta análise, que teve como cenário a sala de emergência da Unidade de Atendimento Pediátrico de um hospital de ensino público. É necessário aprofundamento, a partir de outros temas e em outras instituições.

Por meio da análise qualitativa, foi possível destacar, a partir dos dados analisados, uma realidade dinâmica e integradora das ações da enfermagem no atendimento de emergência à criança, sendo identificado o tema central deste estudo: a enfermeira como mediadora do atendimento à criança em situação de emergência. Essa atuação integradora revela-se a partir da atividade de planejamento de recursos humanos e materiais, das atividades assistenciais como a admissão e avaliação da criança em situação de risco e da assistência à criança e a sua família.

Tendo em vista a temática desenvolvida neste estudo, não cabem aqui generalizações, mas, sim, a tentativa de compreender como as enfermeiras atuam num ambiente de trabalho assistencial centrado em procedimentos técnicos e tecnológicos, em que a habilidade, o tempo, a tomada de decisões, o trabalho de equipe, a liderança e a capacitação são fundamentais para alcançar um objetivo comum, que é recuperar ou salvar a vida de uma criança numa situação de emergência. 
REFERÊNCIAS BIBLIOGRÁFICAS

1. World Health Organization. Call of action to the attention integrated to the prevalentes discases of the children. 2001. Available at: URL:<http://www.who.int/chd/imci-sd/ callacts.htm>

2. Pavelqueires S. Educação continuada de enfermeiros no atendimento inicial à vítima de traumatismos. [Dissertação] Ribeirão Preto (SP): Escola de Enfermagem de Ribeirão Preto/ USP; 1997.

3. Minayo MCS. Ciência, técnica e arte: o desafio da pesquisa social. In: Minayo M, Deslandes S, Neto O, Gomes R. Pesquisa social. teoria, método e criatividade. 6. ed. Rio de Janeiro (RJ): Vozes; 1996. p. 9-29.

4. Ministério da Saúde (BR). Diretrizes e normas regulamentadoras de pesquisas envolvendo seres humanos. Brasília (DF): Ministério da Saúde; 1996.

5. Minayo MCS. O desafio do conhecimento. Pesquisa qualitativa em saúde. 7. ed. São Paulo (SP): Hucitec; 2000.

6. Bardin L. Análise de conteúdo. Lisboa: Edições 70; 1977.

7. Gomes R. A análise de dados em pesquisa qualitativa. In: Minayo M, Deslandes S, Neto O, Gomes R. Pesquisa social. teoria, método e criatividade. 6. ed. Rio de Janeiro (RJ): Vozes; 1996. p.67-80.

8. Granitoff N. Whitaker I. Dalossi T. Conçalves V. Sistema racional de atendimento - um modelo de assistência ao paciente em parada cardio respiratória. Acta Paul Enfermagem 1994 abril; 8(2/4):7-12.

9. Universidade São Paulo. Faculdade de Medicina de Ribeirão Preto. Hospital das Clínicas. A inserção de um hospital universitário público no sistema único de saúde: a experiência do Hospital das Clínicas da Faculdade de Medicina de Ribeirão Preto da Universidade de São Paulo. São Paulo (SP); 2002.

10. Kitt S, Selfridge-Thomas J, Proehc J, Kaiser J. Emergency nursing practice. Philadelphia: Mosby; 1995.

11. Pavelqueires S. Introdução. In: Pavelqueires S. Manobras avançadas de suporte ao trauma. São Paulo (SP): Legis Summa; 1997.

12. Wehbe G, Galvão C. O enfermeiro de unidade de emergência de hospital privado: algumas considerações. Rev Latino-am enfermagem 2001 março; 9(2):86-90.

13. Wong D. Impacto da doença crônica, incapacitante ou da morte sobre a criança e a família. In: Wong D. Enfermagem pediátrica. 5. ed. Rio de Janeiro (RJ): Guanabara Koogan; 1999. p. 467-505.

14. Serrano A, Pacheco A, Perez A, Peña A, Arranz C. Algunas recomendaciones para la aplicación práctica de la resucitación cardiopulmonar en domicilio. Emergencias 1997 marzo-abril; 9(2):122-6.

15. Wong D. Influências da família na promoção da saúde da criança. In: Wong D. Enfermagem pediátrica. 5. ed. Rio de Janeiro (RJ): Guanabara Koogan; 1999.p.53-72.

16. Granitoff N. Reanimação cardiorrespiratória - Aspectos relacionados à dinâmica de atendimento no Pronto-socorro de um Hospital de Ensino. [Dissertação]. São Paulo (SP): Escola Paulista de Medicina/UFSP; 1995.

17. Pérez A. Reanimación cardio-pulmonar en Pediatría. Editorial. Emergencias 1999 junio; 11(5):335-7.

18. American Academy of Pediatrics. American Heart Association. Suporte avançado de vida em pediatria. Dallas (TX): American Academy of Pediatrics/American Heart Association; 1997.

Recebido em: 11.2.2003

Aprovado em: 1.10.2003 